\section{Vision and Light Sensitiveness.}

In my former letter (NATuRE, April I4, p. 498) I endeavoured to avoid dogmatism on this very obscure subject, and aimed rather at stimulating further research in what seems to be a phenomenon of great importance. Though I go all the way with Mr. Locket (Nature, April 28, p. 570) in cautioning the utmost reserve in accepting my hypothesis, especially as, in my letter, it is supported, and designedly so, by no more definite evidence than the flicking of a fly; still, in the interests of research, I feel called upon to add some comments to his letter.

I have collected a large mass of evidence which, however, cannot be published yet, as it is far from complete. Moreover, as much of it appears to contradict the conclusions of great authorities, some of whom Mr. Locket mentions, it obviously cannot be urged until I have repeated each essential portion of it more than once, and explored in each experiment every possibility.

First of all, then, I submit that it is of the utmost importance to differentiate clearly between sensitiveness to light and vision, both in experiment and in deduction; for vision is by means of eyes, light sensitiveness not necessarily so. Plateau has proved (Journal de l'Anat. ef de la Physiol., I886, p. 43I) that certain myriapods distinguish between light and darkness by the general surface of the skin; though Forel and Lord Avebury have proved this not to be the case with ants. It would be interesting to know if it is so in Typhlopone, where there are no eyes. Wherever there are eyes I think we may, for the present, assume that there is sensitiveness to light, but this is far different from presuming that there is vision. I have been unable to discover any evidence for vision in the Epeiræ studied, or in Tegenaria domestica or Agelena labyrintheca, when proper precautions have been taken. In these instances a fly, with the wings cut off, will not disturb them: but, if the fly have wings or stumps of wings with which it can buzz in the forceps then the case is very different. The necessity for taking every precaution may be shown by the extreme sensitiveness of $T$. domestica to the presence of carbon dioxide, so that even slight breathing on the specimen causes movement. Though this spider will revive after a collapse of five minutes in a vacuum at $6 \mathrm{~mm}$. of mercury, though it will live for some minutes apparently with comfort in coal gas, an atmosphere of carbon dioxide kills it instantly.

Another precaution, most essential to success, is to avoid casting shadows on the animal under observation; in the case of the black-bellied tarantula (Lycosa narbonnensis), and in very many others, there is a manifest seeking for light. This is most apparent when the young are on the parent's back. Here, possibly, lies the solution of this enigma. This spider carries her young on her back with, so far as I can see, no food for about six months. These fasting youngsters grow strong, expend energy, and certainly do not become emaciated. Do they get their energy from the air alone? Do they possibly get it from the sun, as vegetable life does? I cannot yet answer this. Here the investigation would extend from the pigment-spot in Euglena viridis to the facts of modern heliotherapy.

Turning to Mr. Locket's remarks on the ants, the species employed for the most part were Formica fusca and $F$. sanguinea. In these insects Forel (Rec. Zoolog. Suisse, I 887) has proved that there is normally serisitiveness to light which is destroyed by varnishing the eyes, and Lord Avebury mentions ("Ants, Bees, and Wasps," I3th edition, p. 405) their sensitiveness to " ultra-violet rays much beyond our limits of vision." This same authority says quite plainly (op. cit. pp. $273,272,266,256,25 \mathrm{I}$ ) of Lasius niger that, "though it seems clear that they are helped by sight," they do not trust much to their eyes, and are "little guided by . . . surrounding objects." In another experiment, " if she [the ant] were much aided by sight, then she would have had little difficulty in finding her way back." On the other hand, he concludes from further work (pp. 268, 270) that by altering the position of the lights "the ant went wrong," and that, " in determining their course the ants are greatly influenced by the direction of the light." Here the difference between mere light sensitiveness and vision is strongly supported.

Forel's experiment ("Senses of Insects," pp. I24-I28), noted by Mr. Locket, had seemed to me conclusive until I repeated it, taking care to supply several control ants the eyes of which were varnished with a transparent fluid. From the results I concluded that the difficulty in finding home was as much due to the annoyance of being handled and varnished as to being hoodwinked.

When working on the flies, including both species mentioned by Mr. Locket, I did not varnish the eyes; I used a second sheet of glass between the fly's back and the moving object. Still this experiment with the second glass was not repeated often enough to allow me to state my results with assurance, and I agree with Mr. Locket that varnish should have been employed. With regard to the motion of air,-and this is the kernel of Commander Hilton Young's hypothesis, - vibration due to sound waves and simple air currents must be treated separately. Many insects and spiders are extremely sensitive to the former, and there can be no doubt that the fly is sensitive to the latter, though I doubt whether to the extent suggested by Commander Hilton Young.

I cannot agree with Mr. Locket in his use of the ocelli as an explanation. It was, I think, Johannes Müller's opinion that they were especially useful for close vision. But we have the authority of Plateau, Forel, Réaumur, Marcel de Serres, Dugès, Lord Avebury, and others, that varnishing of these organs made no difference. Though many, with Forel (Rec. Zoolog. Suisse, I887), Lebert ("Die Spinnen der Schweiz"), and Pavesi (Ann. Mus. Civ. di Genova, I873, p. 344), suggest that the ocelli serve for vision in semi-darkness, and the eyes for vision in full light, the experiments I have made in this field, necessarily obscure, have been fruitless, so far as I have been able to devise them.

The instance of the male Attid, given by $\mathrm{Mr}$. Locket, I have not worked on yet; as well as the many examples of what appears to be lethal fascination as in Mantis religiosa. There is clearly an enormous amount of work to be done,-- so far I have not touched the scorpions,--and I speak, as I did in my former letter, only of those species which I have studied, necessarily few relative to the vast kingdom under discussion. So I can end no better than again, with Mr. Locket, cautioning reserve.

\section{St. Beuno's College, St. Asaph, April 29.}

\section{Phosphorescence caused by Active Nitrogen.}

In a letter under this title in Nature of May 5, p. 599, Prof. E. P. Lewis announces his recent discovery that active nitrogen excites phosphorescence in a number of solid compounds. I should like to mention that during the summer of last year I observed the same phenomenon in the case of an 